AGH DRILLING, OIL, GAS • Vol. 33 • No. 2 • 2016

http://dx.doi.org/10.7494/drill.2016.33.2.495

Dan Paul Ştefănescu*, Oki Ari Maulidani**, Beryl Audrey**

\title{
COMPRESSOR APPLICATION \\ FOR EXTENDING PRODUCTION LIFE CYCLE \\ IN MATURE FIELDS
}

\section{INTRODUCTION}

Laslau Mare gas field is located in the central part of the Transylvanian Basin, Romania (Fig. 1). The field has 49 active producing gas wells. The field has been producing dry gas ( $99 \%$ methane) for more than 40 years by natural depletion with no active water drive. The porosity range from $6-10 \%$ and the permeability range from $0.1-1 \mathrm{mD}$. The current recovery factor is $74.5 \%$.

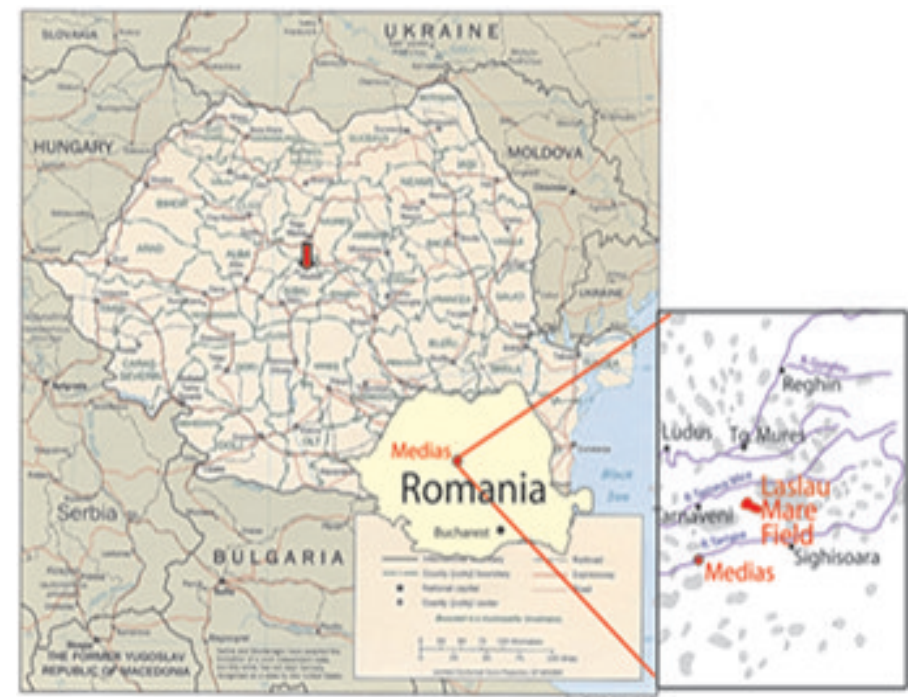

Fig. 1. Laslau Mare field location

* Exploration-Production Department, Romgaz, Romania

** SPM Schlumberger, Romania 
The reservoirs are formed of sandstones with carbonate cement, interbedded with shale layers. The depth of the gas saturated reservoirs varies between $1800 \mathrm{~m}$ and $3000 \mathrm{~m}$ TVD.

The 49 active producing wells are divided into 5 group stations based on their location as shown in the Figure 2. Every well has its own individual underground separator which is located in the group station in order to separate water based on gravitational principal.

All the gas production from the 5 groups then enter the drying station where adsorption process occurs using silica gel to remove any remaining associated water. Afterwards, Laslau Mare gas production is compressed together with other fields' gas production in the Filitelnic then Tigmandru compression stations in order to meet national sales pressure. The national sales pressure is in the range of 25-30 bars while the pressure in the drying station is in the range of 7-10 bars.

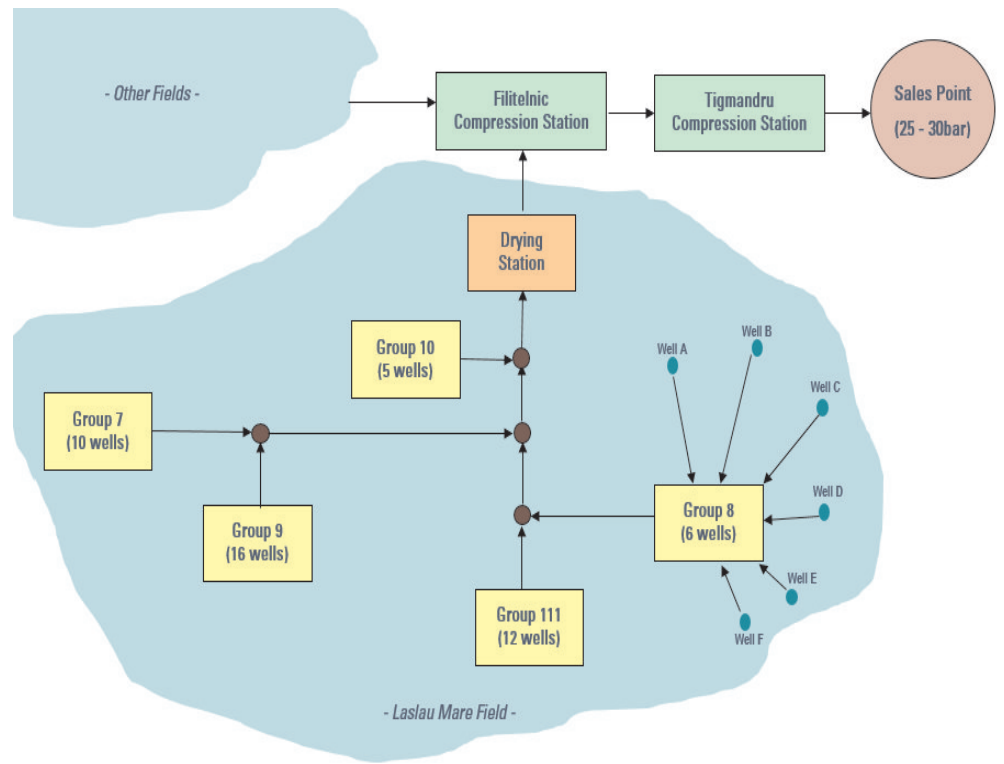

Fig. 2. Laslau Mare gathering system

\section{LASLAU MARE FIELD CHALLENGES}

The focus of this paper is to address two main challenges in Laslau Mare field which are reservoir backpressure causing liquid loading and highimpact on production based on the external pressure.

Turner and Coleman characterized loading as occurring when droplets of liquid in the tubing either rise (not loaded) or fall against the flow (loaded). They balanced the weight of liquid droplets vs. the upward drag force from the flow of gas. The gas 
production velocity and corresponding rate to just support the droplets and keep them from falling and accumulating in the bottom of the well is referred to as the critical velocity or rate.

The Turner equation correlated to well data with surface pressures generally much more than 1000 psi while Coleman equation correlated to well data with surface pressures generally less than 1000 psi. Therefore, Coleman equation is more suitable for Laslau Mare liquid loading analysis as the current maximum surface pressure is around 150 psi.

Coleman equation [3] to calculate critical gas velocity is

$$
U=1.59 \frac{\sigma^{1 / 4}\left(\rho_{L}-\rho_{g}\right)^{1 / 4}}{\rho_{g}^{1 / 2}}
$$

where:

$U-$ minimum gas velocity in units of $\mathrm{ft} / \mathrm{s}$,

$\sigma-$ surface tension in units of dynes/cm,

$\rho_{l}-$ liquid phase density in units of $\mathrm{lbm} / \mathrm{ft}^{3}$,

$\rho_{g}-$ gas phase density in units of $\mathrm{lbm} / \mathrm{ft}^{3}$.

Assuming that the surface tension of water is 60 dynes/cm, liquid phase density of water is $67 \mathrm{lbm} / \mathrm{ft}^{3}$, gas gravity is 0.6 and gas average temperature is $120 \mathrm{~F}$, the equation can be expressed as a function of pressure [3], where $p$ is in units of psia.

$$
U=4.43 \frac{(67-0.0031 p)^{1 / 4}}{(0.0031 p)^{1 / 2}}
$$

When the well is flowing above its critical velocity, it is predicted that droplets are being carried up by the gas velocity and are not accumulating in the well. If the well is flowing below its critical velocity, then it is predicted that droplets are not being carried upward and are accumulating in the well.

Figure 3 shows Coleman unloading rate for well producing Water at various tubing sizes [3]. The graph clearly shows that the critical gas rate is proportional to the flowing wellhead pressure. In the other words, when wellhead pressure increases then critical rate will be higher which will give a "pseudo" production decline of the wells.

Laslau Mare wells are completed mostly with $27 / 8$ " tubing. The corresponding critical gas rate at $150 \mathrm{psi}$ flowing pressure is $500 \mathrm{Mcf} / \mathrm{d}(14 \mathrm{kscm} / \mathrm{d})$ where $70 \%$ of current gas rates in Laslau Mare field are less than that.

The next Laslau Mare field challenge is highly dependent on the external pressure. It is observed that every 1 bar higher of field pressure, field gas production decreases around $20 \mathrm{kscm} / \mathrm{d}$ as shown in the Figure 4. The reason of higher field pressure mainly 
due to higher sales pressure and/or Filitelnic/Tigmandru compression stations don't work at full capacity.

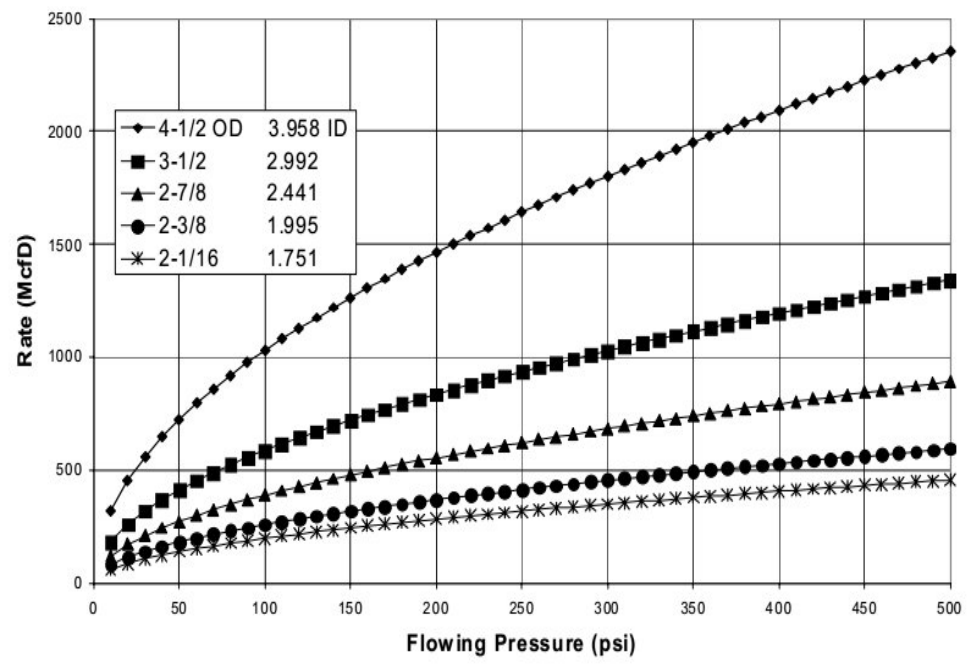

Fig. 3. Coleman unloading rate [3]

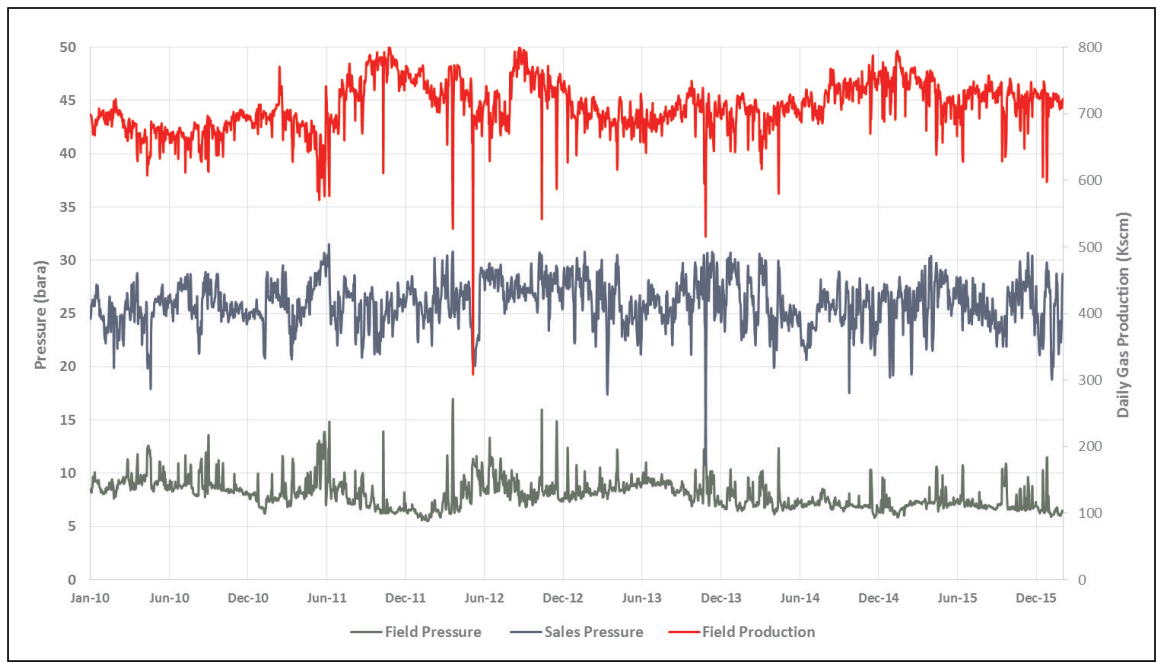

Fig. 4. Laslau Mare field performance

\section{COMPRESSOR PRINCIPALS}

Gas compressor is a mechanical device that increases the pressure of a gas by reducing its volume. Gas compressor can be classified in two broad categories depending 
on the manner in which pressure energy is imparted to the gas; positive displacement and dynamic compressor [1].

In the positive displacement compressor, gas is physically trapped between two relatively moving components and forced to occupy lower volume, thereby increasing its pressure. The sub categories of positive displacement compressor are reciprocating and rotary screw compressor.

In the dynamic compressor, a rotating component imparts its kinetic energy to the gas which is eventually converted into pressure energy. The sub categories of dynamic compressor are centrifugal and axial compressor.

The benefit of gas compressor is to transport gas to the sales point such as Filitelnic and Tigmandru compression stations. When gas compressor is installed in the wellhead, it will help to reduce wellhead pressure which increases the gas velocity above the critical velocity as well as it reduces the bottomhole flowing pressure. The wells will be capable of unloading the liquid inside the wellbore and the reservoir will suffer a higher pressure drawdown which means higher gas production. Moreover, the wells will not be impacted by the external pressure fluctuation as long as this latter is below the compressor discharge pressure.

\section{WELLHEAD AND GROUP COMPRESSORS}

Installing one big field compressor in the drying station might be the very first answer appeared to overcome the challenges in Laslau Mare field. It is like an extra barrier when the Filitelnic and/or Tigmandru compression stations don't work at full capacity. Unfortunately, as pilot project, the operational risk is considered high and requires high investment cost as well.

Wellhead compressor has been introduced in Laslau Mare field since 2010 whereas group compressor has been introduced since 2014 (Fig. 5). Wellhead compressor type is reciprocating type while group compressor is rotary screw one. Reciprocating compressor is suitable for low gas rate and high pressure while rotary screw compressor is suitable for continuous flow and low pressure [1].

The advantages of wellhead compressor are relatively low operational cost, maximum drawdown as it is closer to the well, and easy to be moved from one well to another when required. However, the wellhead compressor is very limited in term of compressed volume, around $17 \mathrm{kscm} /(\mathrm{d} \cdot \mathrm{unit})$. It also requires changes at the wellhead for the installation and it is prone to shut down for engine maintenance.

In the other side, group compressor has ability to compress multiple wells in the same group as long as the volume doesn't exceed $60 \mathrm{kscm} /(\mathrm{d} \cdot \mathrm{unit})$. It doesn't require changes at wellhead and the operation is uninterrupted as the unit will be standby in the group at any time. Nevertheless, the disadvantages of group compressor are having higher capital expense, large footprint in the group, and less drawdown compared to wellhead compressor as the result of additional pressure drop from wellhead to group station. 
a)

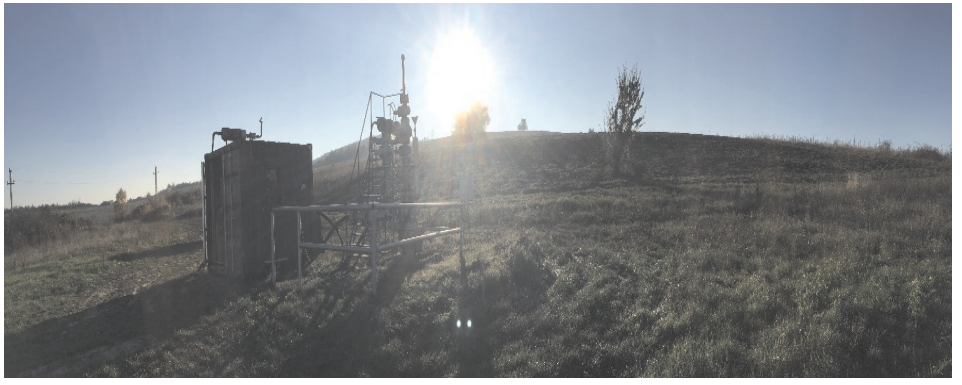

b)

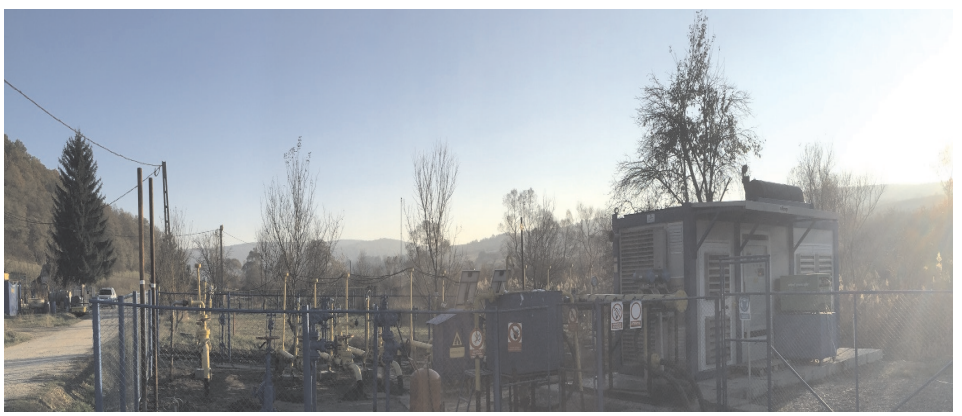

Fig. 5. Wellhead compressor (a) and group compressor (b) in Laslau Mare field

\section{CANDIDATE SELECTION}

There are two practical steps to select the candidates for gas compressor in Laslau Mare field. The first step is to analyze the historical production performance whether the well is reactive to pressure changing or not. The Laslau Mare wells are classified into 3 categories regarding responsiveness to pressure changing; high, medium, and low category.

High category means the wells are really reactive to pressure changing. The gas production significantly decreases when the pressure increases. The population is $20 \%$ of total wells in Laslau Mare field. Medium Category, which is $40 \%$ population, indicates that the wells are also reactive to pressure changing but the impact is not as significant as high category. Low Category shows the wells which are not reactive to pressure changing. These wells just follow a normal decline at any time. The example of production performance for each categories can be found in the Figure 6 .

The second step is to simulate the individual well production performance using Schlumberger PIPESIM software. The benefits of this exercise is to get the expected incremental gas production by sensitizing the wellhead pressure values. As mentioned before, installing gas compressor will help to reduce wellhead pressure which eventually should increase gas production. It helps to justify the economic analysis before installing gas compressor. 
a)

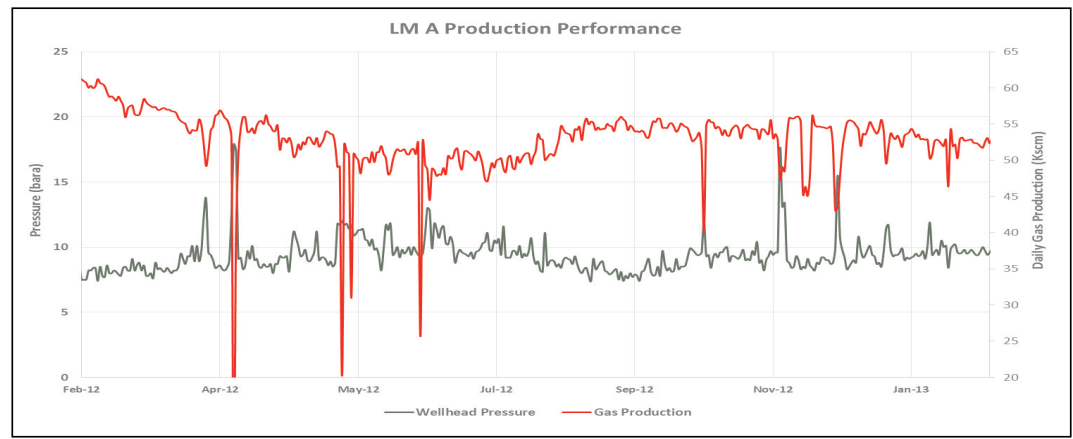

b)

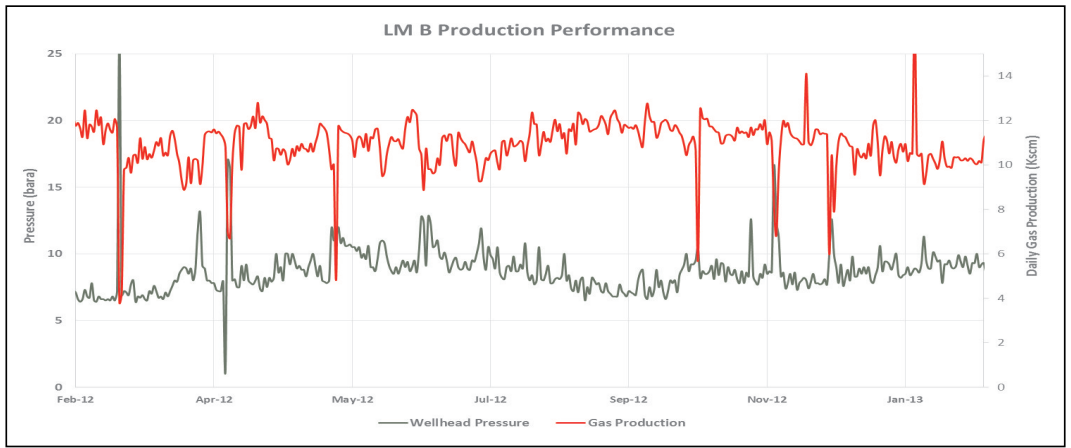

c)

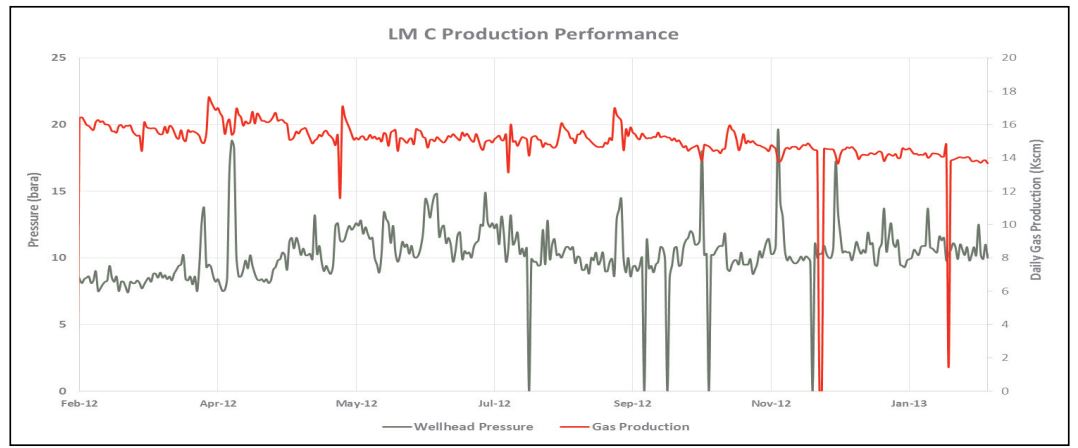

Fig. 6. High category well (LM A) (a), medium category well (LM B) (b), and low category well (LM C) (c)

Figure 7 shows the example of Nodal analysis for high reactive and low reactive well at 3 different wellhead pressures; 3 bars (purple line)*, 8.5 bars (red line), and 13 bars (grey line). For high reactive well, gas rate significantly increases when wellhead pressure decreases. Conversely, gas rate is insignificantly different when wellhead pressure decreases for low reactive well.

The clear difference of low reactive and high reactive well is at the location of the nodal points. The low reactive well has nodal points almost at end of IPR

* Colour version on CD. 
(inflow performance relationship) curve. Therefore, reducing wellhead pressure will give insignificant impact of gas production. In the other side, high reactive well has nodal points a bit further to the left side. Hence, some incremental gas production is observed when the wellhead pressure is lower.

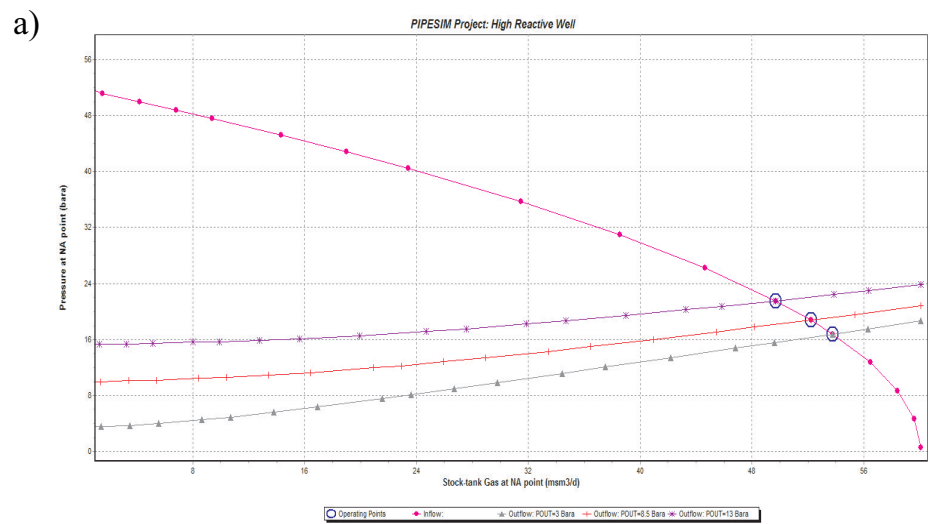

b)

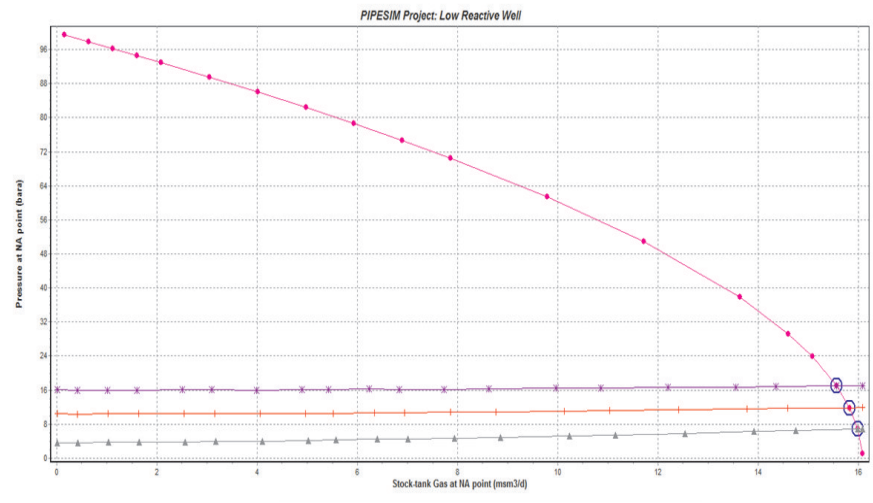

Fig. 7. Example of nodal analysis for high reactive (a) and low reactive (b) well

When analyzing closely the performance of each well, it is observed that high-reactive wells have lower skin compared to low-reactive wells. It means that gas compressor is the appropriate solution to increase gas production for low skin wells. High skin wells will not be reactive to pressure change as the perforation intervals is blocked. In this case, stimulation operation such as acidizing or fracturing would be the solution.

\section{COMPRESSOR PERFORMANCE}

Five units of wellhead compressor have been installed since 2010 in Laslau Mare field and giving in average of $15 \mathrm{kscm} / \mathrm{d}$ incremental gas production. The average payout 
equivalent gas production is $6 \mathrm{kscm} / \mathrm{d}$. Payout equivalent gas production represents the operational cost and gas consumption of the 5 unit's compressors (Fig. 8).

LM X is the example of successful wellhead compressor application in Laslau Mare field. Looking at the well performance history, the well is significantly reactive to pressure changing. The wellhead compressor has been installed in this well since 2013 as indicated by lower wellhead pressure (Fig. 9). The positive result has been observed by gaining around $8 \mathrm{kscm} / \mathrm{d}$ incremental of gas production.

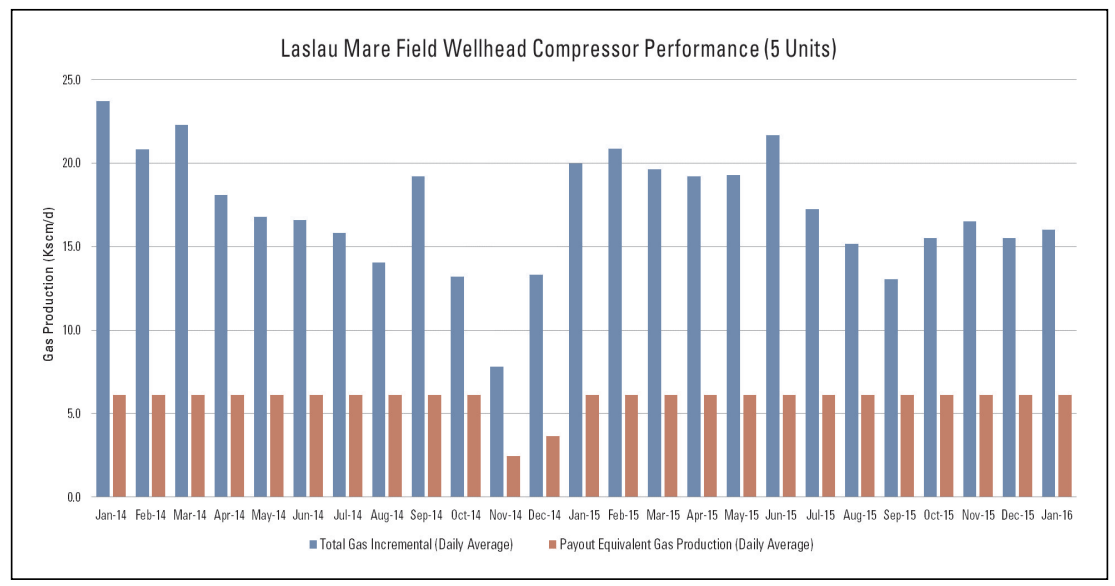

Fig. 8. Wellhead compressor performance in Laslau Mare field
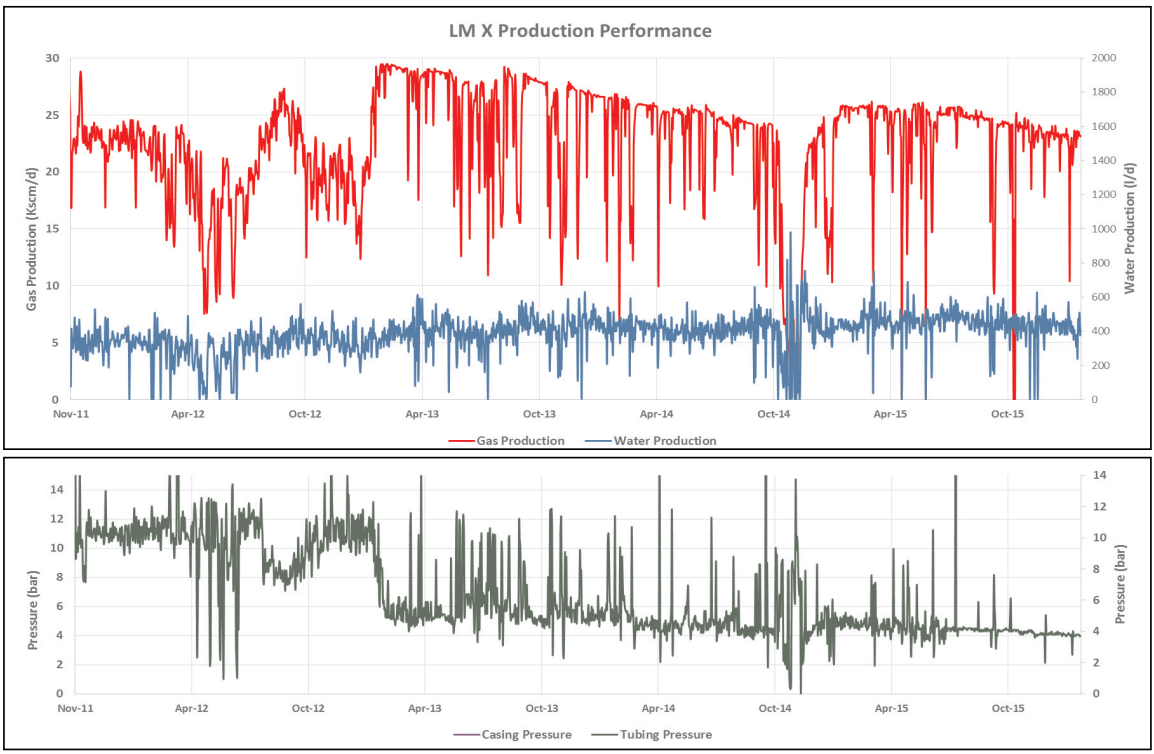

Fig. 9. LM X production performance 
The well could have declined rapidly if the compressor wasn't installed back in 2013. The gas production might drop to 0 at the end of 2013 by extrapolating its high decline rate. Thus, it is proven that gas compression does extend the production life cycle.

The application of group compressor has been started since September 2014 in group 9 station only. The average incremental gas production is $8 \mathrm{kscm} / \mathrm{d}$ with payout equivalent gas production of $4 \mathrm{kscm} / \mathrm{d}$ (Fig. 10). Currently, only one well (LM A) is connected to the group compressor as the gas rate is by now at the limit, $60 \mathrm{kscm} / \mathrm{d}$. When the wellhead pressure is lower as the result of decreasing group pressure, gas production increases subsequently. This condition surely extends its production life cycle and improve the final gas recovery factor (Fig. 11).

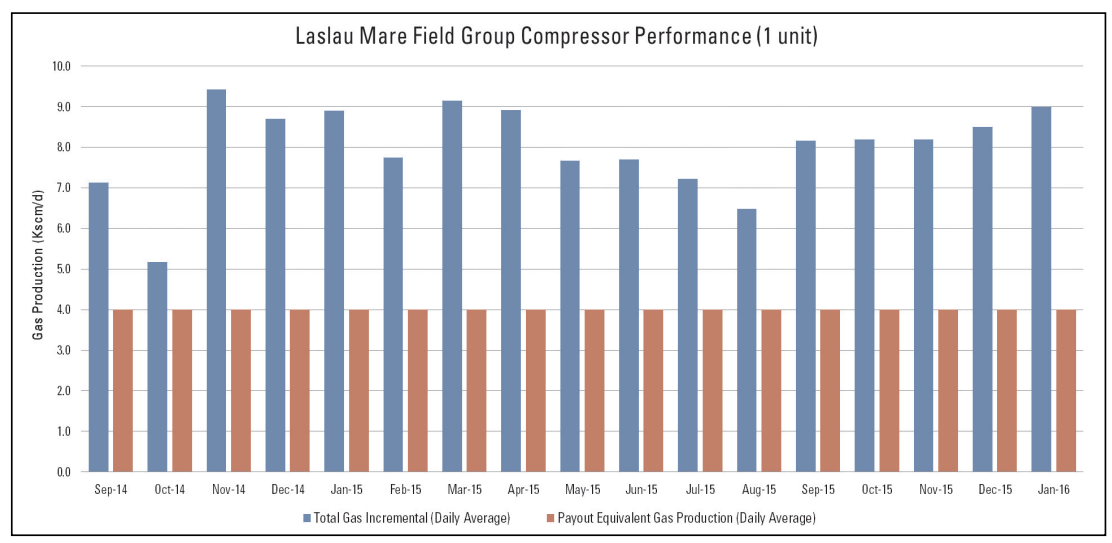

Fig. 10. Group compressor performance in Laslau Mare field

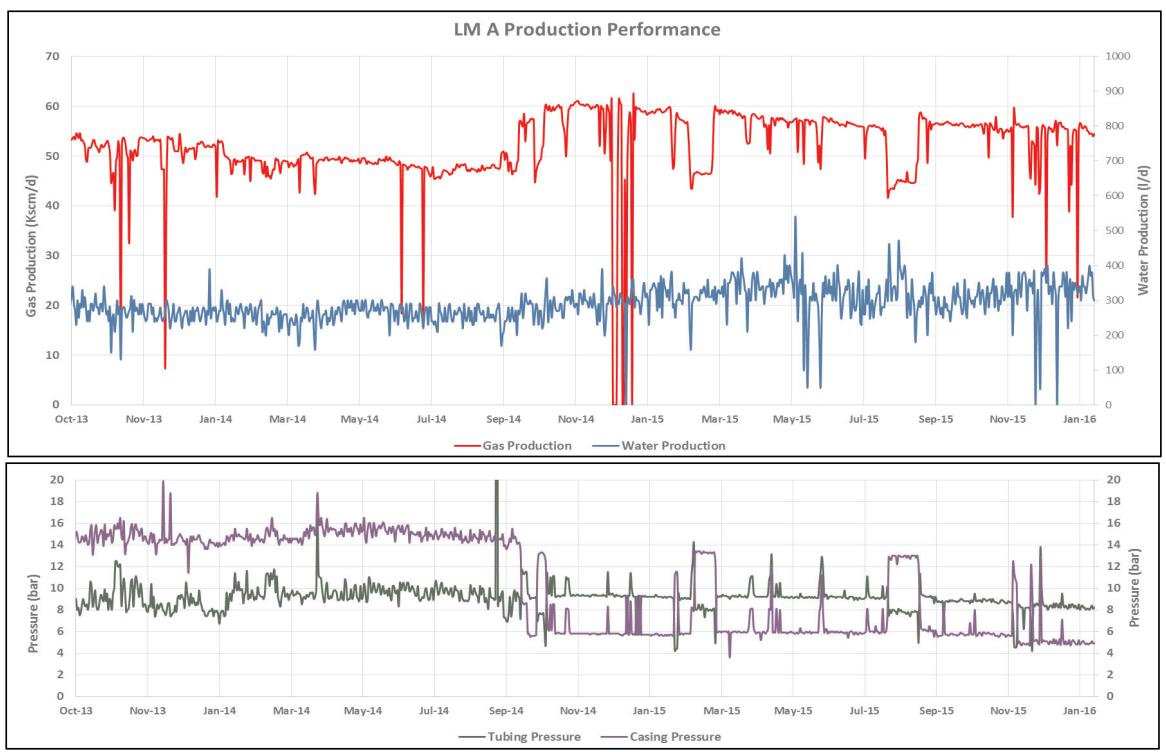

Fig. 11. LM A production performance 


\section{COMPRESSOR CHALLENGES}

Some challenges have been observed while implementing group and wellhead compressor in Laslau Mare field. Below are the main factors:

- Modifying wellhead and group station to install gas compressor usually is challenging due to accessibility and/or weather condition.

- Once the compressor is installed, it might take up few weeks to fine-tune the compressor parameters so the units are working at optimum condition.

- The process to find the best candidate have been performed and will be reviewed periodically based on wells' performance. Therefore, re-allocating wellhead compressor from one well to another is required. Lifting operation must be performed safely as the unit is fairly heavy (5 tons).

- High field pressure reduces the wellhead compressor performance.

- Regular engine maintenance has to be performed especially for reciprocating type.

- Some units were down due to suspected foamy liquid entered into the compressor. Foam is created by the soaping operations performed on daily basis. It happened as the wells were soaped to help unloading process. As an action item, injecting defoamer in the inlet line of compressor have been implemented since 2015 and it works perfectly.

- Less drawdown for group compressor due to high pressure drop from wellhead to group station.

\section{CONCLUSIONS}

- Laslau Mare mature gas field is having liquid loading issue and highly dependent on the external pressure.

- Field production performance and well modeling are keys to select the best candidate.

- Compressor should be designed to meet current and future requirements.

- Both wellhead and group compressors have been successfully implemented to extend production life cycle of Laslau Mare field.

- Average of $15 \mathrm{kscm} / \mathrm{d}$ incremental from 5 wellhead compressors since 2010.

- Average of $8 \mathrm{kscm} / \mathrm{d}$ incremental from 1 group compressor since 2014.

\section{WAYS FORWARD}

- Install gas compressor in the other 4 group stations.

- Further feasibility study to implement field compressor in Laslau Mare field. 


\section{Acknowledgements}

The authors would like to thank the management of ROMGAZ and SPM Schlumberger for the support given to implement compressor application in Laslau Mare Field. Also, the authors would like to thank the IRCAT Company for supplying the compressor.

\section{REFERENCES}

[1] Littlefield R.: Gas Compression Design and Operation. SPE: 9996. 1982.

[2] Clayton R.: Overview of Laslau Mare Surface Facilities. 2008

[3] Coleman S.B, Clay H.B., McCurdy D.G, Norris, H.L. III: A New Look at Predicting Gas-Well Load Up. Journal of Petroleum Technology, March, 1991. 